\title{
Targeted Population-wide Mental Health Support is Essential During COVID-19 Pandemic
}

\author{
Dinesh K Arya* \\ Yarralumla, Australia
}

Article Info

\section{Article Notes}

Received: May 2, 2020

Accepted: May 21, 2020

\section{*Correspondence:}

Dr. Dinesh K Arya, MBBS, MD, DPM, MRCPsych, DM, FRANZCP, CHMS, DipHSM, MBS, FRACMA, FACHSE, AFNZIM, MBHL, GAICD, EMPA, Master Black Belt Lean Six Sigma, Psychiatrist, Yarralumla Professional Suites, Yarralumla ACT 2600, Australia; Telephone No: 0262823899; Email: D.Arya@outlook.com.au.

(c) 2020 Arya DK. This article is distributed under the terms of the Creative Commons Attribution 4.0 International License.

\section{Keywords}

Disaster

Pandemic

Mental health support

\section{Abstract}

To manage COVID-19 pandemic, most nations have been proactive in introducing wide-ranging measures to prevent its spread, as well as to support the economy. During this pandemic, almost the entire population has been impacted by quarantine and social isolation-related restrictions. It is this aspect that makes this pandemic different from other recent disasters.

It is essential that appropriate mental health support is targeted to support people with suspected and confirmed COVID-19 infections, as well as for the health professionals caring for this cohort. During the pandemic it is also essential that access to appropriate mental health support for those experiencing mental disorders is increased, and that appropriate psychosocial support is available for those experiencing financial hardship resulting from quarantine and social isolation-related restrictions so that they can sustain themselves.

\section{Introduction}

In face of a disaster, mental health and psychosocial burden for the affected population is known to increase several-fold. This impact also continues for many years after the disaster event $t^{1}$. Even when a disaster is localised to a geographical region, the unaffected population is also impacted psychologically and emotionally, even though the majority of people are able to continue their lives without too much obvious disruption. Reactions in the unaffected population can range from sympathy, fear, anxiety, depression and even guilt.

The COVID-19 pandemic is different from recent disasters as the effect of this pandemic is real for entire nations ${ }^{2}$. In this pandemic a small section of the population is directly infected, however, most are living with a concern that they may get infected. The direct impact on individuals, communities and entire nations is also real as they are experiencing social isolation ${ }^{3}$. It may be too early to predict the overall consequences of this pandemic, although the impact of social isolation now and into the future is not difficult to imagine ${ }^{4}$.

Early indication is that the impact of COVID-19 pandemic on economies, and therefore on lives of the people, is going to be unprecedented ${ }^{5}$. This is the reason why various governments have chosen to be proactive to introduce economic packages and other mechanisms to stimulate the economy, Australia being a good example ${ }^{6}$.

\section{Gearing Up The Mental Health System}

As COVID-19 has spread across borders, many health systems have activated clear plans to manage this emerging pandemic 
emergency. This has meant an immediate increase in capacity for the health services to be prepared to respond to those who are likely to be directly affected. Plans are progressing to increase the number of intensive care beds and also increase the number of health professionals ${ }^{7}$. New channels are also beginning to open up for the affected population to have access to psychological support and interventions via the use of technology, including through on-line platforms ${ }^{8}$. Many individuals in the community are also coming up with innovative ways to come together to improve connectivity through social media.

To respond to the COVID-19 pandemic consistently and effectively it is important that the response strategy ensures access to mental health resources and support for the entire population.

It is worthwhile to consider strategizing the mental health response for the five sections of the population. The first and second target groups have to be those directly affected by a disaster ${ }^{9-12}$. In this pandemic, these are the patients with suspected and confirmed COVID-19 and the health professionals who are caring for them. As the mental health response is escalated for these two groups, it is critical to be cognisant that the stress response following public health emergencies lasts for a long time after the public health emergency is over ${ }^{13,14}$. Secondly, mental health care and support must be integrated with essential medical care provision. Clinicians and clinical units providing the intensive care and emergency department response may not have had the opportunity to receive prior training to manage and mitigate the emotional distress of patients, their carers and health provider colleagues in relation to COVID-19. Therefore, it is important that mental health professionals are there to support both recipients and providers of care at this time ${ }^{15}$.

Then there are three other groups that must not be forgotten. People with severe mental illnesses in need of mental health and some psychosocial support from public mental health services; people experiencing high frequency mental health disorders, albeit of mild to moderate severity, in need of clinical support from within primary care and private mental health sector; and the general population who have been receiving, or are likely to receive, psychosocial support, including financial, welfare, housing and other community supports, to sustain themselves.

As far as these three groups are concerned, it is absolutely essential that there is no deterioration in access, support and treatment for the first group; that strategies are put in place to ensure continuing access of mental health support for the second group in the immediate term, and there is an escalation of this support in the postpandemic stage; and significant escalation of psychosocial support is needed for the third group during the pandemic, with de-escalation of this support post-pandemic ${ }^{16}$. Even though effective communication and coordination of responses across all three sectors is essential to minimize any wastage of resources, incorrectly timing the escalation and de-escalation of support across the three groups has the potential to result in greater waste ${ }^{17}$.

Mental health care and provision is predominantly professional-dependent. During a pandemic, ensuring continuing access to appropriate mental health professionals will be essential.A key determinant of a mental health response being effective will be the availability of mental health professionals. However, the mix of mental health professionals for the above three suggested categories of patients may need to be different. Not aligning the supports needed by patients with the appropriate personnel also risks wastage of precious resources at this time. For example, for the first group there is a need to develop a surge capacity of mental health specialists and hospital infrastructure. For the second group some additional specialist and significantly enhanced counseling support will be needed. For the third group, voluntary and non-mental health psychosocial support will need to be significantly enhanced. This, coupled with clear policies and guidelines, appropriate training and supervision and ensuring consistency of response and resource allocation will be essential.

Even though it may be possible for the deployment of mental health response to occur locally, the strategy does need to be developed and rolled out centrally. Whether it is an economic stimulus package, measures to increase ICU capacity, acquisition and distribution of personal protective equipment or strategies to provide enhanced mental health support, it must be strategized centrally. Initiating local initiatives risks an inconsistent, varying and possibly ineffective response as it may occur without necessary forethought about resource requirement or length of time for which such a response may need to be sustained. Even though interventions initiated locally may be well targeted to meet immediate needs, these might be difficult to sustain unless these are part of a well-resourced strategy, and therefore risk failing in the longer term.

\section{Tackling Impact of Social Isolation}

Many of the disaster mental health strategies tried in the past are relevant in managing the mental health response to the COVID-19 pandemic. However, the element of social isolation must be a significant additional consideration to develop both immediate and longer-term strategies to mount an effective mental health response. Governments across the world have also been proactive in stopping movement of people and declared lockdowns of communities, cities and regions. An important consequence of this has been social isolation. Staying at home to remain safe has been a message perpetuated by all sides of 
politics, organised media and the health profession. Lack of availability of a vaccine to prevent and treat symptoms of COVID-19 are cited are cited by governments as justifications for implementing social isolation measures to prevent its spread. This has been generally accepted by the public, although governments have also chosen to reinforce this necessity by imposing fines ${ }^{18-20}$.

However, it is important to remain cognizant of the fact that social isolation can have long term consequences for the quarantined population ${ }^{21,22}$. Previous studies have also identified association of quarantine with poorer mental health ${ }^{23-25}$. There is also some indication of long term effects on healthcare workers who are quarantined ${ }^{24-26}$. In addition to the association of symptoms of acute stress with quarantine in both patients and caring health professionals, quarantined staff are also significantly more likely to report exhaustion, detachment from others, anxiety when dealing with febrile patients, irritability, insomnia, poor concentration and indecisiveness, deteriorating work performance, and reluctance to work or consideration of resignation $^{3,27,28}$. Many post-traumatic stress symptoms can also persist for many years ${ }^{29,30}$.

Restriction of movement, reduced contact with family and friends as well as needed or perceived forced isolation, can also increase fear and stress. Uncertainty about the availability of supplies for day-to-day sustenance as well as uncertainty about access to medical care and prescriptions can add to this distress ${ }^{31}$. It is also known that loss of routine and inability to pursue day-to-day activities can also lead to frustration ${ }^{32}$. The impact of quarantine measures on the economy is also likely to be significant ${ }^{33}$. For individuals and families who have to precipitously stop working and as a result experience financial hardships, the effect is going to be long lasting and will remain a risk factor for mental distress and symptoms of mental disorders ${ }^{34}$.

A requirement to quarantine and remain in social isolation will be a cause of extreme moral discomfort for some. Deprivation of liberty and freedom, as well as the breakdown of democratic consultation and decisionmaking processes that many would have struggled to achieve over their lifetime, would be perceived to have been compromised with such a requirement. Many would find this to be particularly confronting. Even though management of such a public health emergency does require deviation from usual democratic norms, if there is a lack of information on why particular decisions are made, a sense of helplessness can emerge.

To minimise the impact of quarantining and social isolation, it is important to consider measures that are likely to be useful during the pandemic, and also after the pandemic. Longer periods of quarantine are known to be associated with higher levels of emotional distress.
Therefore, it is important to ensure that the duration of quarantine is kept to the minimum where possible and that strategies are implemented to provide opportunities to break complete social isolation. Use of technology to increase social interaction and participation in social activities and events during quarantine are important. Extension of quarantine is known to be particularly frustrating as it tends to exacerbate demoralisation ${ }^{35}$. If it is possible such last-minute extensions should be avoided.

It is critical to focus on those with pre-existing poor mental health and mental health vulnerabilities, who are in quarantine as they are known to experience higher level of emotional distress ${ }^{36}$. During a pandemic this subgroup of population may need targeted assistance. Postpandemic, return to work arrangements for this group of the population may need to include additional mental health support, assistance and treatment.

\section{Conclusions}

Many governments have taken bold and assertive steps to manage the COVID-19 pandemic. This has included measures to shut down mass gatherings, introduction of social distancing, encouragement of self-isolation and also enforced quarantine. As support for all those affected by the pandemic is being ramped up, it is important to remember that the mental health impact of these measures can be substantial and long lasting. The need for appropriate mental health support must not be under-estimated.

During a pandemic and more importantly post pandemic, it is important that mental health support is augmented and de-escalated at appropriate time for specific groups of the population.

It may not be possible to develop discrete strategies to meet the needs of individuals, however, five groups are identified who may have specific and discrete mental health needs and time trajectories when the impact of additional mental health support is likely to be most value adding.

The impact of social isolation, financial hardships and breakdown of social connectivity on individuals and communities is likely to be prolonged even after the COVID-19 pandemic is over. Both the acknowledgement of the impact on people's mental health, as well as the implementation of specific mental health strategies to address the negative impact of isolation, will be important.

\section{References}

1. Shoaf K, Rotiman SJ. Public Health Impact of Disasters Australian Journal of Emergency Management. 2000; 15(3): 58-63.

2. Zhou X. Psychological crisis interventions in Sichuan Province during the 2019 novel coronavirus outbreak. Psychiatry Res. 2020; 286 (February): 112895.

3. Brooks SK, Webster RK, Smith LE, et al. The psychological impact of 
quarantine and how to reduce it: rapid review of the evidence. Lancet. 2020; 395(10227): 912-20.

4. Andersson L. Loneliness research and interventions: a review of the literature. Aging Ment Health. 1998; 2(4): 264-74.

5. Amadeo K. Coronavirus, Ebola, and Plague: How Disease Outbreaks Affect the Economy 2020 [Available from: https://www.thebalance. com/coronavirus-plague-ebola-economic-impact- 4795744 .

6. Economic Response to the Coronavirus [press release]. 2020

7. McCauley D. 'Can't take foot off the pedal': ICU capacity ramped up while coronavirus spread slows. The Sydney Morning Herald. 2020.

8. Turner-Cohen A. Coronavirus Australia: \$1.1 billion mental health, domestic violence package. Newscoau. 2020.

9. Lee SM, Kang WS, Cho AR, et al. Psychological impact of the 2015 MERS outbreak on hospital workers and quarantined hemodialysis patients. Compr Psychiatry. 2018; 87: 123-7.

10. Li Q Guan X, Wu P, et al. Early Transmission Dynamics in Wuhan, China, of Novel Coronavirus-Infected Pneumonia. . N Engl J Med. 2020.

11. Gardner PJ, Moallef P. Psychological impact on SARS survivors: Critical review of the English language literature. Canadian Psychology/ Psychologie canadienne. 2015; 56(1): 123-35

12. Goldmann E, Galea S . Mental Health Consequences of Disasters. Annu Rev Public Health. 2014; 35(1): 169-83.

13. Fan F, Long K, Zhou Y, et al. Longitudinal trajectories of post-traumatic stress disorder symptoms among adolescents after the Wenchuan earthquake in China. Psychol Med. 2015; 45: 2885-28896.

14. Cheng SKW, Wong CW, Tsang J, et al. Psychological distress and negative appraisals in survivors of severe acute respiratory syndrome (SARS). Psychol Med. 2004; 34: 1187-95.

15. Mohammed A, Sheikh TL, Poggensee G, et al. Mental health in emergency response: Lessons from Ebola. Lancet. 2015; 2(11).

16. Lund C, Brooke-Sumner C, Baingana F, et al. Social determinants of mental disorders and the Sustainable Development Goals: a systematic review of reviews. Lancet Psychiatry. 2018; 5(4): 357-69.

17. Ogden J. Do no harm: Balancing the costs and benefits of patient outcomes in health psychology research and practice. J Health Psychol. 2019; 24(1): 25-37.

18. NYPD to hand out fines for violating social-distancing rules amid coronavirus, de Blasio says [press release]. 2020.

19. Schmunk R. British Columbians now face $\$ 25 \mathrm{~K}$ fine, jail if they ignore public health orders over COVID-19. CBC News. 2020.

20. Chung F, Clench S, McMahon E. Coronavirus Australia live updates: NSW imposes new, on the spot $\$ 5000$ fine. Newscomau. 2020.

21. Rubin GJ, Wessely S. The psychological effects of quarantining a city. BMJ. 2020; 368: m313.
22. Brooks SK, Webster RK, Smith LE, et al. The psychological impact of quarantine and how to reduce it: rapid review of the evidence. The Lancet. 2020; 395(10227): 912-20.

23. Hawryluck L, Gold WL, Robinson S, et al. SARS control and psychological effects of quarantine, Toronto, Canada. Emerg Infect Dis. 2004; 10: 1206-12.

24. Marjanovic Z, Greenglass ER, Coffey S. The relevance of psychosocial variables and working conditions in predicting nurses' coping strategies during the SARS crisis: an online questionnaire survey. Int J Nurs Stud. 2007; 44: 991-98.

25. Reynolds DL, Garay JR, Deamond SL, et al. Understanding, compliance and psychological impact of the SARS quarantine experience. Epidemiol Infect. 2008; 136: 997-1007.

26. Wu P, Liu X, Fang Y, et al. Alcohol abuse/dependence symptoms among hospital employees exposed to a SARS outbreak. Alcohol. 2008; 43: 706-12.

27. Bai Y, Lin CC, Lin CY, et al. Survey of stress reactions among health care workers involved with the SARS outbreak Psychiatr Serv. 2004; 1055-7.

28. Liu X, Kakade M, Fuller CJ, et al. Depression after exposure to stressful events: lessons learned from the severe acute respiratory syndrome epidemic Compr Psychiatry. 2012; 53: 15-23.

29. Wu P, Fang Y, Guan Z, al. e. The psychological impact of the SARS epidemic on hospital employees in China: exposure, risk perception, and altruistic acceptance of risk Can J Psychiatry. 2009; 54: 302-11.

30. Cava MA, Fay KE, Beanlands HJ, et al. The experience of quarantine for individuals affected by SARS in Toronto. Public Health Nurs. 2005; 22: 398-406.

31. Blendon RJ, Benson JM, DesRoches CM, et al. The public's response to severe acute respiratory syndrome in Toronto and the United States. Clin Infect Dis. 2004; 38: 925-31.

32. Hawryluck L, Gold WL, Robinson S, et al. SARS control and psychological effects of quarantine, Toronto, Canada. Emerg Infect Dis. 2004; 10: 1206-12.

33. Hutt R. The economic effects of COVID-19 around the world. 2020.

34. Jeong H, Yim HW, Song YJ, et al. Mental health status of people isolated due to Middle East respiratory syndrome. Epidemiol Health. 2016; 38.

35. Rona RJ, Fear NT, Hull L, et al. Mental health consequences of overstretch in the UK armed forces: first phase of a cohort study. BMJ Case Rep. 2007; 335: 603.

36. Cukor J, Wyka K, Jayasinghe N, et al. Prevalence and predictors of posttraumatic stress symptoms in utility workers deployed to the World Trade Center following the attacks of September 11, 2001. Depress Anxiety. 2011; 28: 210-7. 